\title{
doispontos:
}

\section{Ernst Platner e a história pragmática da alma}

\section{Ernst Platner and the pragmatic history of the soul}

\section{Luis Fellipe Garcia}

Doutor em Filosofia pela Université Catholique de Louvain; Pesquisador pós-doutorando da Fundação Alexander von Humboldt na Ludwig-Maximilians - Universität de Munique

luisfellipegarcia@gmail.com

Resumo: Este estudo é uma exploração da concepção de lógica como uma "história pragmática da alma [pragmatische Seelengeschichte]", tal como é formulada pelo médico e filósofo alemão Ernst Platner. Da análise dessa fórmula, pretende-se extrair um esboço do modo como ele concebe as noções de: alma, história, lógica e filosofia. Para tanto, o argumento será estruturado como uma análise: (i) da alma enquanto objeto de estudo da lógica; (ii) da história pragmática enquanto método de estudo da lógica; e (iii) da compreensão da relação entre lógica e filosofia extraída por Platner dessa abordagem. O objetivo deste trabalho não é fazer uma avaliação crítica da teoria de Platner, mas antes fazer um esboço do horizonte de questões que se abre a partir dessa compreensão da porta de entrada da filosofia - a lógica - como uma espécie de história da alma.

Palavras-chave: alma; história; lógica; filosofia; metafísica.

Abstract: This study is an exploration of the conception of Logic as a "pragmatic history of the soul [pragmatische Seelengeschichte]", as formulated by the German physician and philosopher Ernst Platner. From this formula, we aim to extract a sketch of Platner's conception of the soul, history, logic and philosophy. The argument is structured as an analysis: (i) of the soul as the object of study of logic; (ii) of the pragmatic history as the method of study of logic; (iii) of the comprehension of the relation between logic and philosophy that Platner extracts from this approach. The aim of this study is not to critically evaluate Platner's theory, but rather to sketch the horizon of questions opened by this comprehension of the entrance of philosophy - the logic - as a history of the soul.

Keywords: soul; history; logic; philosophy; metaphysics. 


\section{Introdução}

Ernst Platner, médico e filósofo, conhecido como o precursor da medicina psicossomática e considerado por alguns autores como o primeiro pensador ocidental a empregar o termo "inconsciente" de forma substantivada ${ }^{1}$, professor e fonte de inspiração de grandes nomes da história da filosofia, como Johann Gottlieb Fichte e Friedrich Wilhelm Joseph von Schelling, chama o seu projeto científico em que une os seus conhecimentos médicos e filosóficos de antropologia, a qual ele caracteriza como uma exploração das "ligações, restrições e relações recíprocas" entre o corpo, objeto de estudo da anatomia e da fisiologia, e a alma, objeto de estudo da lógica, da psicologia, da estética e de boa parte da filosofia moral ${ }^{2}$. Em outras palavras, uma antropologia que se apresenta como um estudo das determinações recíprocas entre corpo e alma, entre medicina e filosofia moral.

Se esse projeto de exploração das determinações recíprocas entre medicina e filosofia moral, entre a doutrina do corpo e a doutrina da alma, resulta em uma imagem original do que seja a medicina, proporcionando mesmo a constituição de todo um método de circunscrição e abordagem de problemas que passou a ser conhecido pelo nome de medicina psicossomática (um estudo das múltiplas relações entre a natureza corpórea e a natureza psíquica do homem), resulta igualmente de seu projeto uma imagem consideravelmente original do que seja a filosofia, a qual é compreendida como um estudo do homem tomado tanto enquanto potências e capacidades que se manifestam no corpo, como enquanto alma aspirante à felicidade (PLATNER, 1772, p. iii). Essa ciência, a filosofia, é apresentada alguns anos mais tarde como uma ciência cuja primeira parte é a lógica, entendida como "a história pragmática da alma [pragmatische Seelengeschichte]” (PLATNER, 1776, p. i).

O objetivo deste estudo é destrinchar esta fórmula empregada por Platner: uma "história pragmática da alma [pragmatische Seelengeschichte]", a fim de delinear o modo como ele concebe as noções de: alma, história, lógica e filosofia. Para tanto, propõe-se explorar: (i) a alma como objeto de estudo da lógica; (ii) a história pragmática como método de estudo da lógica; e (iii) a compreensão da relação entre lógica e filosofia extraída por Platner dessa abordagem. Cabe notar que o nosso objetivo aqui não é fazer uma avaliação crítica da teoria de Platner, mas antes fazer um esboço do horizonte de questões que se abre a partir dessa compreensão da porta de entrada da filosofia - a lógica - como uma espécie de história da alma.

\footnotetext{
${ }^{1}$ O termo "inconsciente" substantivado (Unbewusstsein) é de fato usado por Platner no aforismo 140 de seus Aforismos Filosóficos na versão de 1793, no contexto da discussão sobre representações não-conscientes (bewusstlose Vorstellungen), onde ele afirma que as representações não-conscientes são "por um lado, causa, e por outro, efeito das [representações] conscientes" e assim "a vida da alma humana é uma série contínua de representações articuladas, sob a variação do consciente e do inconsciente [das Leben des menschlichen Seele ist eine stetige Reihe, unter dem Wechsel von Bewusstsein und Unbewusstsein, verknüpfter Vorstellungen]" (PLATNER, 1793, \$140). Além desse uso substantivado, Platner emprega com frequência o adjetivo unbewusst. Passagens desse tipo fazem com que Platner seja considerado por estudiosos como Karl Joachim Grau como o responsável por cunhar o termo "inconsciente" (GRAU, 1922, p. 63). Essa mesma tese é retomada na coletânea dirigida por Ludger Lütkehaus (1979, p. 20), e mais recentemente por Angus Nicholls e Martin Liebscher (2010, p. 9). Bem entendido, isso não significa que o termo tenha a mesma espessura semântica que vai adquirir a partir do desenvolvimento da psicanálise, mas simplesmente que o problema da formação da consciência a partir da não-consciência se torna uma questão filosófica central no período. Para uma reconstrução detalhada do papel dessas questões no surgimento posterior da psicanálise, ver: VAYSSE, 1999.

${ }^{2}$ A divisão entre os três grupos de disciplinas é apresentada nos seguintes termos por Platner: "pode-se considerar primeiro as partes e ocupações [Geschäfte] da máquina, sem observar as restrições experimentadas por esses movimentos em relação à alma, nem o que a alma por sua vez sofre em relação à máquina; isso é a Anatomia ou Fisiologia. Em segundo lugar, pode-se explorar justamente as forças e propriedades da alma, sem levar em consideração a ação conjunta do corpo ou as mudanças resultantes na máquina; isso seria a Psicologia ou, o que é o mesmo, a Lógica, a Estética e uma grande parte da Filosofia Moral. [...] Finalmente, pode-se considerar corpo e alma em suas ligações, restrições e relações recíprocas [in ihren gegenseitigen Verhältnissen, Einschränkungen und Beziehungen], e isso é o que eu chamo de Antropologia” (PLATNER, 1772, pp. xv-xvii).
} 


\section{I - A alma}

No seu trabalho Antropologia para médicos e sábios, publicado em Leipzig em 1772, Platner mostra como a Antropologia, esse estudo das relações recíprocas entre corpo e alma, pode contribuir tanto para o estudo do corpo, do qual se ocupam os médicos (cujos estudos incluem anatomia e fisiologia), como para o estudo da alma do qual se ocupam os filósofos morais (cujos estudos incluem lógica, psicologia e estética). Segundo Platner, a separação entre esses dois domínios teria prejudicado tanto a filosofia, na medida em que um estudo das relações corpo-alma poderia dar uma importante contribuição para esta "ciência do homem e dos corpos e espíritos que contribuem para a sua felicidade" (PLATNER, 1772, p. iii), quanto para a medicina, na medida em que ela precisa compreender aquele que ela deve curar - o homem. Se o homem é uma harmonia entre corpo e alma, um fracionamento de sua natureza tende a ser prejudicial tanto para o estudo do corpo como para o estudo alma; dever-se-ia, ao contrário, sustenta Platner, explorar como a relação alma-corpo se manifesta no corpo e como essa mesma relação se manifesta na alma - em outras palavras, explorar uma antropologia para médicos e sábios (ou filósofos).

A separação de ambos os domínios viria do preconceito segundo o qual a natureza da alma e sua relação com o corpo seria um segredo escondido e que toda hipótese a esse respeito resultaria em especulações obscuras. Se, de fato, a relação entre ideias e movimentos na matéria parece enigmática, não se pode contudo negar, avança Platner, que há uma certa ligação entre eles, uma vez que das ideias na alma pode resultar um movimento no corpo e que "dos movimentos da matéria, surgem ideias na alma" (PLATNER, 1772, p.x). Em outras palavras, percebe-se um movimento tanto na direção do pensar a partir da extensão material, quanto na direção da matéria a partir do representar na alma: nas palavras de Platner, "minha sensação me diz que da ação de certos objetos resultam ideais em minha alma e das representações na minha alma resultam movimentos no meu corpo" (PLATNER, 1772, p. xii).

Desses primeiros indícios da relação entre os dois domínios, abre-se a possibilidade de: (a) uma exploração da constituição progressiva da interioridade a partir de suas manifestações, isto é, de abordar as manifestações da alma em uma sequência sucessiva, desde a formação das ideias a partir da sensibilidade, passando pela memória, imaginação (Phantasie), até a razão em suas distintas manifestações ${ }^{3}$; e (b) de uma exploração da relação entre a má formação da interioridade e o mau desempenho da exterioridade, isto é, da construção daquilo que Platner denomina uma "teoria das doenças oriundas da tensão do espírito [aus der Anstrengung des Geistes]" - as doenças mentais. Este método abriria, pois, para a medicina, a possibilidade de explorar o modo como a alma (ou o espírito) influencia a constituição e o funcionamento do corpo (estudo das doenças de um ponto de vista psicossomático) e, para a filosofia, a de explorar a constituição progressiva da alma a partir de suas manifestações sucessivas, isto é, a partir de sua história.

Tratar a alma como um objeto de história parece algo bastante original, quando se parte do pressuposto de um isolamento entre uma dimensão suprassensível sem qualquer efeito sobre a sensibilidade e uma dimensão sensível na qual a sucessão, e por conseguinte a história, se constitui. Mas o que Platner defende, desde a sua tese de doutoramento em medicina sobre os fundamentos somáticos da memórias ,é um exame

\footnotetext{
${ }^{3}$ A primeira seção do livro é um estudo dos fundamentos da antropologia, as seções subsequentes (da segunda à quinta) articulam essa sucessão, são elas: (2) Da produção das ideias (von der Erzeugung der Ideen), em que se discute a relação entre impressões sensíveis, atenção, ideias e consciência; (3) Da memória (von dem Gedächtinis), que trata da formação e do papel da faculdade de lembrar (Erinnerung) em sua relação com as ideias; (4) Da imaginação (von der Phantasie), que explora a ligação e a progressão (Fortgang) de ideias; e (5) da razão e suas distintas manifestações (von der Vernunft und ihren verschiedenen Äusserungen), em que se discute a formação de palavras e conceitos gerais - a formação da linguagem - e a progressão racional de ideias. Trata-se, assim, de uma exploração que vai da sensação à linguagem e culmina com a articulação de uma progressão racional.

${ }^{4}$ Trata-se do título da sexta seção do livro: Theorie der Krankheiten, welche aus der Anstrengung des Geistes entstehen.

${ }^{5}$ A dissertação apresentada na Universidade Leipzig tinha o título: De vi corporis in memoria specimen primum, cerebri in apprehendis et retinendis ideis officium sistens. Ela está disponível em formato digital no endereço: $<$ https://reader.digitale-sammlungen.de/en/
} 
desses pontos de articulação entre ideias imateriais e objetos materiais, entre representações na alma e movimentos no corpo - o que afeta tanto o estudo do corpo, na medida em que este é influenciado por uma dimensão imaterial, como o atestam as doenças mentais, quanto o estudo da alma, na medida em que a alma se manifesta na matéria através das atividades humanas.

Essa compreensão da alma e de suas relações com o corpo é desenvolvida em 1776, quando Platner lança a primeira edição de seu livro de filosofia mais influente: os Aforismos filosóficos com algumas diretrizes para a história da filosofia. Uma obra permanentemente em construção, a qual foi reeditada várias vezes sempre sob o mesmo título, mas com modificações consideráveis em cada uma das mais de cinco novas edições. A cada nova publicação, Platner reorganiza seus aforismos para dar conta das novas doutrinas filosóficas de seu tempo, como as de Kant, Reinhold e Fichte.

Em sua primeira versão, os aforismos constituem um estudo da alma, compreendida como a causa das atividades do homem de pensar, sentir, querer e agir"; a alma assim como algo distinto tanto "da máquina do corpo" como "das ideias e sensações". Em função dessa dupla distinção, a alma poderia também ser chamada simplesmente de Eu no duplo sentido de: (a) "uma força de intuir ideais" (distinta portanto das ideias enquanto tais) e (b) algo distinto do corpo e do qual o corpo é ele mesmo "uma propriedade" (PLATNER, 1776, \$\$2-4). A alma é, assim, uma espécie de alicerce comum das ideias (seus efeitos) e do corpo (sua propriedade), e esse alicerce comum não é propriamente um ser, mas uma força.

A alma, esta força basilar comum das ideias e do corpo, servirá de fio condutor para uma investigação dividida em duas partes: a primeira é denominada por Platner de Lógica, e é descrita como uma "história psicológica da faculdade humana de conhecimento" ou uma "história pragmática da alma". É preciso, sublinha Platner, distinguir essa abordagem da compreensão habitual e assaz limitada da lógica como um simples "inventário de regras, de proposições e silogismos" (PLATNER, 1776, p. xi). Com efeito, a lógica, segundo Platner, não deve ser entendida como inventário, mas como uma história; e ela incide não somente sobre regras e proposições, mas sobre a alma. Em outras palavras, trata-se da história da força de intuir ideias, a qual tem o corpo por sua propriedade, uma história que começa pela história dos sentidos, passa pela história de formação e desenvolvimento da imaginação, da memória, da linguagem, e se conclui com a história da razão. A história dessa força humana na sua construção progressiva do conhecimento é precisamente o que Platner chama aqui de Lógica.

A segunda parte da investigação é denominada Metafísica e diz respeito, nas palavras de Platner, a "uma

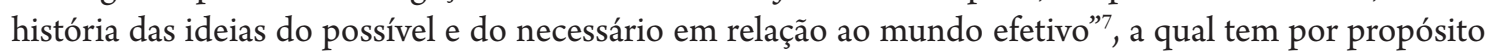
final a teologia e por fundamento a cosmologia (PLATNER, 1776, p. xi). Na medida em que alma é uma força em que se fundam tanto os sentidos e conceitos, como as ideias do possível e do necessário, o estudo da alma é o fio condutor dessa história que nos conduz do exame dos sentidos até as discussões metafísicas mais elevadas sobre o bem e o mal e sobre os seus fundamentos.

Os Aforismos filosóficos são retrabalhados e republicados em 1793, após a publicação das duas edições da Crítica da Razão Pura (1781 e 1787), de modo que Platner pode agora se posicionar em relação a este trabalho que, ao lado do Ensaio filosófico sobre a natureza humana e seu desenvolvimento de Johann Nikolaus Tetens, considerado uma espécie de John Locke alemão, constitui o livro de filosofia que mais

fs1/object/display/bsb10977828_00001.html>. Consultado em:30/04/2019.

6 "O homem pensa, sente [empfindet], quer, age [handelt]. Esses efeitos [Wirkungen] são chamados, de acordo com o uso geral da linguagem, de efeitos da alma [Seelenwirkungen], e a causa desses efeitos [é chamada] de alma” (PLATNER, 1776, \$1).

${ }^{7}$ Subtítulo da seção dedicada à metafísica: Geschichte der Ideen vom Möglichen und Notwendigen in Beziehung auf die wirkliche Welt (PLATNER, 1776, \$\$722-1088). 
lhe despertou o interesse (PLATNER, 1793, p. iv) ${ }^{8}$. Nessa nova versão, a qual tem um profundo impacto sobre a constituição da filosofia de Fichte ${ }^{9}$, Platner divide sua obra novamente em duas partes, mas agora a primeira inclui Lógica e Metafísica e a segunda é inteiramente dedicada à Filosofia Prática, a qual inclui um estudo da Moral, do Direito e da Política.

Na primeira parte, a metafísica é descrita como uma ciência cujos fundamentos são os conceitos e os princípios fundamentais da razão, cujos objetos são o mundo e a relação homem-mundo e cujas finalidades são Deus, a felicidade e a imortalidade (PLATNER, 1793, \$8). A investigação dos fundamentos (dos conceitos e princípios da razão) é denominada Lógica, a qual inclui agora uma investigação de nossas possibilidades de lidar com as grandes questões da cosmologia (mundo), da psicologia (relação homemmundo) e da teologia (Deus e felicidade) (PLATNER, 1793, \$9).

A Lógica é agora definida como "a história pragmática, i. e. crítica, da faculdade humana de conhecimento" (PLATNER, 1793, \$11). O aposto "i. e. crítica" é certamente uma influência kantiana, que faz com que Platner desloque a questão da possibilidade da parte final da investigação a respeito do bem e do mal para a parte inicial a respeito da lógica, compreendida também como uma avaliação das possibilidades do conhecimento humano. Já a substituição da fórmula "história pragmática da alma" por "história pragmática da faculdade de conhecimento" não é ela mesma tão significativa quanto pode parecer à primeira vista. Com efeito, como vimos acima, a noção de "história da faculdade humana de conhecimento (menschliches Erkenntnisvermögen)" já estava presente na primeira versão de 1776 (onde Platner a toma como uma fórmula intercambiável com "história pragmática da alma" ${ }^{10}$ ), de modo que não se pode dizer que essa substituição seja uma influência da crítica kantiana à noção metafísica de alma. Além disso, na nova versão de 1793, Platner afirma categoricamente que não se deve abandonar o conceito de alma, o qual, segundo ele, deve ser tomado incialmente "de acordo com o uso da linguagem comum, como sujeito da consciência", o que é aliás compatível com o "eu penso" kantiano - e se, no sentido filosófico, esse conceito adquire de fato a espessura ontológica de "substância metafísica", isso é algo cuja legitimidade depende da demonstração da verdade desse conceito ao longo do percurso da investigação filosófica (PLATNER, 1793, \$27). Assim, uma vez que a alma é tomada incialmente simplesmente no sentido de sujeito e não de substância metafísica, não haveria motivo para evitar essa palavra já tão consagrada no uso comum da linguagem, "ainda que se provasse a completa nulidade de todos os seus predicados suprassensíveis". Tampouco haveria motivo para substituí-la pela palavra Gemüth (ânimo, mente), pois, com efeito:

a alma é chamada de Gemüth (essa é a palavra kantiana) apenas na medida em que lhe é atribuída uma alteração de sensações e convicções [Gesinnungen]; do mesmo modo que, sob outros aspectos, outros nomes lhe correspondem: espírito [Geist], cabeça [Kopf], coração [Herz], etc. (PLATNER, 1793, \$27).

\footnotetext{
${ }^{8} \mathrm{O}$ texto de Tetens foi publicado em 1777. Sobre as relações entre Tetens e a filosofia transcendental, consultar o novo número da revista Astérion inteiramente dedicado ao tema: PACCIONI, 2018.

${ }^{9}$ Ao longo de seu percurso como professor universitário, Fichte dedicou diversos cursos semestrais completos aos aforismos de Platner de 1793. Esses cursos incluem uma disciplina por semestre durante todo o período que Fichte esteve em Jena (do semestre de inverno de 1794 ao semestre de verão de 1799), um curso ministrado em Berlim no semestre de inverno de 1801 e um curso em 1812 sobre a lógica transcendental em que os Aforismos foram mais uma vez retomados em detalhe - as notas desses cursos estão todas disponíveis no volume 4, série II da Gesamtausgabe de Fichte publicada pela Academia de Ciências da Baviera. A importância desses aforismos no percurso fichtiano é tamanha que a Academia publicou os próprios aforismos de Platner como um volume suplementar da Gesamtausgabe, GA, II, 4-S.

${ }^{10}$ A primeira frase do prefácio de 1776 diz: "as três primeiras seções contêm a história psicológica da faculdade humana de conhecimento ao lado de alguns comentários esboçados sobre a origem, a distinção, e a prevenção de erros, eu diria em uma palavra [que elas contêm] a Lógica, se eu não soubesse que sob esse título costuma-se exprimir mais um inventário de regras, esclarecimentos, classificações, proposições e silogismos do que uma história pragmática da alma" (PLATNER, 1776, p. xi) - os termos "história psicológica da faculdade humana de conhecimento" e "história pragmática da alma" parecem ser empregados aqui de modo intercambiável.
} 
A alma corresponde destarte ao conceito geral de subjetividade (o sujeito da consciência, o Eu), e ela pode ser declinada de diversas maneiras, em função do aspecto que se quer nela ressaltar (a alteração, Gemüth; a espontaneidade, espírito ${ }^{11}$; o intelecto, cabeça; o sentimento, coração; etc.). Este conceito, assim, incialmente identificado à noção de sujeito, só ganha uma espessura metafísica, se a investigação filosófica for capaz de fundamentá-lo enquanto substância, e ainda que a fundamentação falhe, o termo pode continuar a ser empregado no sentido corriqueiro da linguagem de sujeito da consciência.

Se retomamos agora todos os aspectos do conceito de alma formulado por Platner, pode-se dizer que se trata da noção geral de subjetividade, a qual deve ser entendida não como uma coisa, mas como uma força cujos efeitos se manifestam nas atividades de sentir, imaginar, pensar e querer. Essas manifestações externas permitem explorar a alma tanto no que diz respeito às suas manifestações individuais desviantes em um homem (doenças), quanto no que diz respeito às manifestações da formação das capacidades do homem (sentimento, imaginação, pensamento, vontade) - e, neste sentido, no que diz respeito a um domínio de formação irredutível ao individual, na medida em que não se trata da formação das capacidade de um homem, mas da formação das capacidades humanas. A alma é por isso objeto de interesse tanto da medicina, que explora a formação do corpo individual e seus eventuais desvios, como da lógica, que explora a história pragmática da faculdade humana (supra-individual) de conhecer. Finalmente, esta força pode ser equiparada ao próprio Eu, sujeito da consciência, e só adquire uma espessura metafísica dentro da investigação filosófica que se inicia como uma história pragmática da alma, entendida como sujeito da consciência - uma história da consciência.

\section{II - A história-pragmática}

Como vimos até aqui, a alma é uma força cujas manifestações reveladas em seus efeitos (Wirkungen) ou atividades - sentir, pensar, querer, etc. - são o objeto de estudo da lógica, que pode, neste sentido, ser entendida como uma história da sucessão de manifestações dessa força. Tal história, contudo, é caracterizada como uma história pragmática. Vejamos como Platner articula esse tipo de abordagem - esse método investigativo - da alma.

Na primeira versão dos Aforismos filosóficos, a lógica começa por uma investigação sobre a essência da alma ( $\$ \$ 1-105)$, desde a sua efetividade ( $\$ \$ 1-10)$ até o propósito final de sua união com o corpo ( $\$ \$ 90$ 105). Essa abordagem abre caminho para o percurso que se inicia com a história da representação sensível ( $\$ \$ 114-238)$, passa pela história da imaginação [Phantasia] (\$\$239-449) e se conclui com a história da razão ( $\$ \$ 450-721)$. Assim, uma discussão sobre a alma e sua união com o corpo abre caminho para um exame das faculdades de conhecer ordenadas de modo progressivo, da mais inferior (sentidos) à superior (razão) - a conclusão da lógica conduz, por sua vez, à metafísica, onde se articula a história das ideias do possível e do necessário, que é o que há de mais elevado nas ideias da alma (\$\$722-1093). As investigações se concluem com uma exploração da noção de imortalidade da alma entendida agora, ao cabo do percurso, como uma substância simples ( $\$ \$ 1088-1093)$. Assim, a apreensão do propósito final da alma, abre caminho para a organização de uma série progressiva de manifestações - dos sentidos à imortalidade; ou ainda: da alma como sujeito da consciência em formação à alma como substância simples - que articula lógica e metafísica.

Na versão de 1793, Platner acrescenta a seus aforismos uma introdução geral ( $\$ \$ 1-20)$ que começa por uma reflexão sobre os problemas fundamentais formulados pelo homem quando a consciência é nele despertada: o que é o mundo (sua causa, natureza, determinação)? qual é relação do homem com o mundo?

\footnotetext{
${ }^{11}$ Sobre a noção de espírito em Platner, ver em especial os aforismos 3 a 6, em que ele explora a noção de espírito na filosofia e a distinção entre espírito e letra. Esses aforismos têm um especial interesse do ponto de vista da pesquisa fichtiana, pois eles articulam de modo condensado alguns pontos desenvolvidos por Fichte sobre estes temas que desempenham um papel central em seus primeiros trabalhos como Sobre o espírito e a letra em filosofia (recentemente traduzido em português por Ulisses Vaccari e publicado em uma edição com um rico aparato crítico. São Paulo: Humanitas, 2014) e mesmo na Grundlage, como mostrou o excelente trabalho de TORRES FILHO, 1975. Para os comentários fichtianos desses aforismos de Platner, ver GA, II, 4, pp. 41-49.
} 
como lidar com a própria finitude, i. e. com a morte anunciada? Tais problemas, ou enigmas, conduzem ao conjunto de investigações subordinadas a essas grandes questões: a metafísica. A busca pela solução desses enigmas fornece agora o princípio de organização do percurso investigativo, que se articula do seguinte modo: primeiro, exploram-se as possibilidades da faculdade humana de conhecimento em relação às exigências da metafísica, a lógica; e, em seguida, articulam-se o estudo da utilidade da vida terrena, a filosofia moral (subdividida em moralidade, direito e política). Os aforismos são assim divididos em dois livros: (i) lógica e metafísica; e (ii) filosofia moral. A lógica, ou "história pragmática da faculdade humana de conhecimento", começa com uma introdução (\$\$21-26) seguida de uma "divisão das ações da alma" ( $\$ \$ 27-43)$ segundo a faculdade de conhecer a que pertencem, a inferior e a superior, cada uma contendo a sua história: (a) a história da faculdade inferior vai da "história da faculdade de representação dos sentidos" (\$\$46-224) à "história da faculdade de representação da imaginação [Phantasie]" (\$\$225-363); e (b) a história da faculdade superior, "das suas manifestações e tarefas [Verrichtungen]" (\$\$365-648) à sua "essência" ( $\$ \$ 649-718)$ - que trata de seus fundamentos e de sua crítica no sentido kantiano. A metafísica, por sua vez, trata da essência interna do mundo (\$\$727-892) e da causa da perfeição e do mal (\$\$894-1024), e se conclui mais uma vez com uma discussão sobre a imortalidade da alma ( $\$ \$ 1025-1034)$. A história da alma passa, assim, a conduzir dos sentidos à crítica, ao passo que a metafísica é compreendida como uma discussão sobre os fundamentos e causas das representações e do bem e do mal.

Nos dois percursos argumentativos, vê-se como a história pragmática da qual nos fala Platner não constitui uma sucessão qualquer de eventos contados de modo rapsódico, pois há neles um princípio de organização interno, um princípio que orienta a sucessão, de modo que ela deve ocorrer de uma determinada maneira, começando do mais simples e avançando progressivamente ao mais complexo. Este princípio é justamente o propósito final da alma humana. Na primeira versão, de 1776, Platner menciona o propósito da alma em sua união com o corpo, que é "apresentar o mundo como fenômenos adequados à sua natureza e à sua felicidade” (PLATNER, 1776, \$90), e indica que a história da alma conduz justamente à questão da perfeição, a qual é associada à "maior felicidade possível” (PLATNER, 1776, \$939). Essa compreensão adquire uma nova camada semântica em 1793, quando Platner associa o propósito final da alma à busca de uma solução para as questões que a atormentam e das quais, como diz Kant na primeira Crítica, ela não pode escapar: a solução dessas questões está ligada à sua felicidade. O propósito final organizador do percurso histórico-pragmático é, assim, fornecido pelas grandes questões da metafísica: "o enigma do mundo" e da "relação do homem [com o mundo]", donde se extrai "uma série ordenada de investigações" (PLATNER, 1793, \$ 7 ) que conduzem à questão do ser supremo e sua relação com a destinação (Bestimmung) do homem (PLATNER, 1793, \$987).

Em ambas as formulações, vê-se como a história pragmática se articula no interior de um horizonte prático organizado em função de um propósito: a felicidade humana em sua relação com a perfeição e, em 1793, com a solução dos grandes enigmas da metafísica. É por isso que Platner elogia Kant por ter conferido um sentido prático às grandes questões da metafísica, o que, segundo ele, mostra que "a filosofia em seu sentido mais elevado diz respeito à toda a destinação [Bestimmung] do homem” (PLATNER, 1793, \$7). A leitura de Platner sugere, assim, que o sentido prático das grandes questões metafísicas forneceria o princípio a partir do qual lógica e metafísica poderiam ser estruturadas como uma história pragmática.

Essa interpretação é confirmada pela leitura que Platner faz do penúltimo capítulo da Crítica da Razão Pura. A esse respeito, diz ele:

\footnotetext{
Se eu bem entendo o último [sic] capítulo da Crítica kantiana (p. 860ss [A832/B860]), segue-se dele a seguinte exigência para a definição da filosofia: que a sua essência seja determinada (na medida em que ela é um sistema) a partir de seu fim mais completo possível. Por conseguinte, o que importa não é o que a filosofia é segundo essa ou aquela escola, segundo esse ou aquele livro; mas o que ela deve ser segundo o fim principal que a razão pode ter (PLATNER, 1793, \$19).
} 
A página indicada por Platner, assim como o argumento - concernente à filosofia como sistema construído conforme a finalidade da razão - do qual é extraído justamente uma definição de filosofia não como conhecimento histórico (ex datis: "esse ou aquele livro"), mas como conhecimento racional (ex principiis: fim principal da razão), correspondem ao penúltimo capítulo (A arquitetônica da razão pura - A832/ B860) e não ao último como ele diz. O lapso é contudo sugestivo, dado que o último capítulo da Crítica kantiana chama-se A história da razão pura (A852/B880) e que Platner elogia a passagem justamente por ela fornecer uma definição de filosofia a partir do propósito final da razão, abrindo assim o terreno para ele mesmo formular a ideia de uma história pragmática da alma. Com efeito, se a sucessão de manifestações da alma pode ser ordenada conforme a um propósito final, então é possível determinar a posição de cada novo conjunto de manifestações em função do grau de elevação que ele revela em relação ao propósito a ser alcançado. Nesse sentido, essa história da alma é pragmática, na medida em que ela tem um sentido prático fornecido pelo propósito final da razão.

A articulação entre as questões a respeito da força de representar (chamada por Kant de Gemüth) e as questões metafísicas mais elevadas da Razão é facilitada pelo uso geral que Platner faz do termo "alma", o qual se aplica tanto à força de representar (ao Gemüth), como ao princípio organizador interno da filosofia (à Razão). Esse uso geral do termo indica que a história pragmática da alma, na medida em que ela se estrutura de acordo com um princípio da razão (que é ela mesma uma declinação da alma), é estruturada de acordo com um princípio que deve estar presente de modo imanente na própria alma. O princípio imanente dessa história é o que Platner chama de: Trieb (impulso). A noção de Trieb é formulada nos aforismos introdutórios de 1793 nos termos de um impulso de conhecimento do mundo, impulso este que habita no homem, ainda que em alguns deles ele possa não ser despertado (PLATNER, 1793, \$4). Este impulso é o motor imanente da manifestação histórica progressiva das faculdades humanas de conhecimento com vistas a seu objetivo final de articular o saber mais elevado à destinação do homem.

A história pragmática da alma é assim a reconstrução da série ordenada de manifestações da força cognitiva humana, a qual se estrutura em função de seu propósito final - a felicidade, associada à solução dos grandes enigmas da existência: o mundo e a relação homem-mundo - e que contém um princípio imanente de desenvolvimento, chamado por Platner de Trieb (impulso). O impulso de resolver os grandes enigmas da existência - ou, como dizia Aristóteles, o "desejo de saber"12 - é o que constitui o motor imanente da história pragmática, que conduz dos sentidos às grandes questões da filosofia. Em suma, como formula Fichte de modo lapidar em suas aulas sobre o autor dos Aforismos: ao construir sua história pragmática da alma, Platner "filosofa sobre a constituição do filosofar" (FICHTE, GA, II, 4, p. 41).

\section{III - Lógica e filosofia: a história da Razão}

Vimos até aqui que a alma é uma força cujas manifestações sucessivas são ordenadas em função de um propósito prático na direção do qual elas são impulsionadas por um princípio imanente de desenvolvimento chamado de Trieb. Isso nos mostrou: (i) que a alma tem uma história; e (ii) que essa história tem um sentido prático, sendo por isso uma história pragmática. A reconstrução da sucessão das manifestações dessa força em direção à realização de seu propósito prático é o que constitui a história pragmática da alma, ou lógica. Ademais, vimos que o fio condutor dessa sucessão, que conduz dos sentidos às grandes questões da metafísica, é precisamente a noção de alma, entendida em termos suficientemente amplos para abarcar tanto a noção de Gemüth, associada às faculdades cognitivas, quanto a noção de Razão, associada às grandes questões da metafísica. Dessa articulação entre lógica e metafísica no interior de um mesmo percurso, pode-se extrair algumas consequências para a compreensão da filosofia.

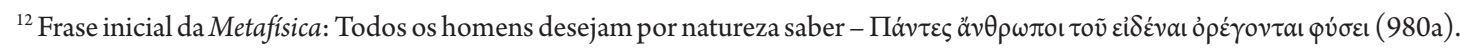


Com efeito, se a alma é um termo geral que pode se aplicar tanto ao Gemüth como à Razão, então é possível articular a história do Gemüth - das atividades cognitivas mais simples até a formulação das grandes questões filosóficas - à uma história da Razão, a qual conteria por sua vez, como diz Kant no último capítulo da $\mathrm{KrV}$, "o conjunto dos trabalhos realizados pela razão" (A852/B880). E é isso precisamente o que Platner faz, na medida em que ele inaugura as suas discussões sobre a metafísica - logo depois da conclusão da Lógica - com uma seção inteiramente dedicada à reconstrução crítica dos sistemas filosóficos que o precederam, de acordo com um critério fornecido pela sua própria concepção do que seja a razão (uma força substancial) - essa seção inaugural da metafísica intitula-se "Sobre o verdadeiro fundamento das nossas representações” (\$\$727-816). Platner reconstrói nela: o materialismo (\$\$747-749), o dualismo (\$\$750-753), o espinosismo (\$\$754-755), o idealismo (\$\$756-760), o leibnizianismo (\$\$761-765), os quais são todos criticados por terem concebido a substância como um permanente existente por si e não como uma força (\$\$766-774). A partir dessa crítica, ele extrai alguns conceitos gerais ( $\$ \$ 775-816)$ : como grandeza, mutabilidade e tempo. Para Platner, a substância é ela mesma força (\$768), e a história pragmática da alma é a história dessa força - desde o seu ponto de partida como força-sujeito até alcançar a sua expressão metafísica como força-substância. Se a lógica é a história pragmática da força-sujeito (\$\$21718); a metafísica começa com a história pragmática da força-substância (\$\$719-1050).

Platner retoma aqui algo que ele extraiu de sua leitura de Kant, a saber, uma distinção entre: (i) filosofia, entendida como a apreciação da faculdade humana de conhecimento; e (ii) exposições filosóficas, entendidas como o modo como sistemas filosóficos se organizam e se estruturam para lidar com as questões da razão (PLATNER, 1793, pp. viii-ix); partindo dessa distinção, pode-se então formular um critério - Kant diria uma pedra de toque - com base no qual pode-se filosofar sobre outras filosofias. Por conseguinte, se na lógica Platner "filosofa sobre a constituição do filosofar", como o notou Fichte, ele inaugura a sua metafísica filosofando sobre outros modos de filosofar e começa a construir assim, ainda que de modo rudimentar, uma filosofia da história da filosofia.

Pode-se dizer, assim, que Platner relê a crítica da razão da perspectiva de uma história da razão recontada a partir de um princípio imanente fornecido pela própria faculdade humana de conhecer, um princípio que, como vimos acima, tem um sentido prático. Todas as exposições filosóficas ou, como diz Platner, todos os edifícios doutrinários (Lehrgebäude) podem agora ser ordenados e criticados com base na natureza da razão e em seu propósito prático - e isso inclui o próprio Lehrgebäude da filosofia kantiana (PLATNER, 1793, pp. viii-xiii). Além disso, como a alma é um termo geral que inclui tanto a força cognitiva como a razão em seus interesses pelos grandes enigmas metafísicos, a história da alma reúne a construção progressiva do filosofar (a lógica) e a construção progressiva das filosofias (o início da metafísica) em uma mesma história - lógica e metafísica estão assim articuladas na história da alma (entendida tanto como Gemüth quanto como Razão).

Cabe notar ainda que, de modo assaz significativo, o primeiro movimento argumentativo de Platner em 1793, ao apresentar o seu conceito de lógica como história pragmática da faculdade humana de conhecimento, é buscar reabilitar a noção de dialética, a qual é compreendida por Kant, segundo Platner de modo "desconcertante", em um registro puramente negativo como uma "lógica da aparência", o que contradiz a compreensão habitual do conceito em um registro positivo, como se vê em Platão, em Aristóteles, em Cícero, e de modo paradigmático nos estoicos (PLATNER, 1793, \$21). A separação entre analítica e dialética, iniciada pelos leitores medievais de Aristóteles e recuperada por Kant resultou em uma separação radical entre, de um lado, a história da faculdade cognitiva humana e de seus limites (o que ele chama de psicologia) e, de outro, o inventário de regras do pensar e suas aplicações (o que ele chama de lógica no sentido habitual). Seria apenas uma rearticulação de ambas, as quais devem ser avaliadas criticamente para evitar o seu mau uso, o que permitiria uma recuperação positiva da noção de dialética e uma melhor compreensão do que seria a lógica. Em outras palavras, essa reabilitação da dialética é fundamental para a compreensão da 
lógica como uma história da alma humana, que conduz dos sentidos às mais diversas filosofias dentro do horizonte de satisfação do propósito prático da razão. Não cabe aqui fazer uma reconstrução detalhada dessa reabilitação da dialética; para os nossos propósitos, basta ressaltar que tal reabilitação desempenha um papel central na leitura da história da alma como uma história que articula lógica e metafísica.

Do ponto de vista da totalidade do percurso platneriano, vê-se, assim, que a história do filosofar e a história dos sistemas filosóficos são reunidas e articuladas no interior da história da alma, a qual constitui uma série ordenada de acordo com um princípio interno imanente, um impulso (Trieb), impulso este que faz com que essa força de representar, esse Eu (essa alma), se desenvolva progressivamente na direção de seu propósito prático de alcance do sistema do conhecimento e da felicidade do homem. Por isso, segundo Platner, um dos maiores méritos da filosofia de Kant foi o de ter formulado um conceito de filosofia não de acordo com o que uma ou outra escola diz, mas de acordo com o propósito final da razão, o que permite compreender que só existe uma filosofia e que as doutrinas devem ser estruturadas e organizadas dentro desse grande edifício no interior do qual os homens buscam alcançar a sua finalidade última - o que a filosofia de Kant permite articular, assim, é a noção de que a história da filosofia é ela mesma a manifestação da filosofia entendida como uma história pragmática da alma. 


\section{Referências bibliográficas:}

GRAU, Karl Joachim. 1922. Bewusstsein, Unbewusstes, Unterbewusstes. Munique: Rösl.

FICHTE, Johann Gottlieb. 1962-2012. “Zu Platners „Philosophischen Aphorismen“ Vorlesungen über Logik und Metaphysik”. In: Gesamtausgabe der Bayerischen Akademie der Wissenschaften, Série II, volume 4. Stuttgart: Fromann-Holzboog.

KANT, Immanuel. 1787. Kritik der reinen Vernunft - zweite hin und wieder verbesserte Auflage. Riga: Johann Friedrich Hartknoch.

LÜTKEHAUS, Ludger. 1979. »Dieses wahre innere Afrika «: Texte zur Entdeckung des Unbewußten vor Freud. Frankfurt am Main: Imago.

NICHOLLS, Angus \& LIEBSCHER, Martin. 2010. Thinking the unconscious: Nineteenth Century German Thought. Cambridge: Cambridge University Press.

PACCIONI, Jean-Paul (org.). 2018. Tetens et la philosophie transcendantale. Phychologie, philosophie transcendantale et perfectibilité. In: Astérion, n. 18. [URL: https://journals.openedition.org/asterion/3097]

PLATNER, Ernst. 1767. De vi corporis in memoria specimen primum, cerebri in apprehendis et retinendis ideis officium sistens. Lipsiae: Ex Officina Breitkopfia.

PLATNER, Ernst. 1772. Anthropologie für Ärzte und Weltweise. Leipzig: Dyckischen Buchhandlung.

PLATNER, Ernst. 1776. Philosophische Aphorismen: nebst einigen Anleitungen zur philosophischen Geschichte. Leipzig: Schwickertschen Verlag.

PLATNER, Ernst. 1793. Philosophische Aphorismen: nebst einigen Anleitungen zur philosophischen Geschichte - ganz neue Ausarbeitung. Leipzig: Schwickertschen Verlag.

TORRES FILHO, Rubens. 1975. O espírito e a letra: A crítica da imaginação pura em Fichte. São Paulo: Ática.

VAYSSE, Jean-Marie. 1999. L'inconscient des modernes - essai sur l'origine métaphysique de la psychanalyse. Paris: Gallimard. 